\title{
Oral Bacteria of Children with Turner Syndrome
}

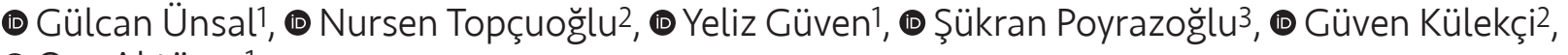 \\ (D) Oya Aktören 1
}

1istanbul University Faculty of Dentistry, Department of Pediatric Dentistry, İstanbul, Turkey

2istanbul University Faculty of Dentistry, Department of Oral Microbiology, İstanbul, Turkey

3istanbul University Faculty of Medicine, Deparment of Pediatric Endocrinology and Metabolism, İstanbul, Turkey

\begin{abstract}
Aim: Turner syndrome (TS) is a genetic disorder caused by a numerical or structural aberration of the X chromosome, which is associated with a female phenotype. Concerning oral status, several studies have revealed that girls with TS have dental anomalies and periodontal problems. The aim of this study was to evaluate the effects of oral bacteria on caries prevalence and periodontal status in pediatric patients with TS.

Materials and Methods: Twenty TS patients and 17 healthy girls were examined for cariological and periodontal status. The levels of mutans streptococci (MS), lactobacilli (LB), yeast and 10 different periodontal bacteria were determined by using culture and microarray techniques in children's stimulated saliva samples.

Results: There was no difference in salivary flow rate and buffering capacity, decayed-missing-filled teeth, MS, LB, or yeast levels between the groups. Plaque index and gingival index levels were significantly higher in the Turner group and dft was significantly higher in the control group ( $p<0.05)$. As a result, microarray analysis, Prevotella intermedia, Fusobacterium nucleatum, Eikenella corrodens, Aggregatibacter actinomycetemcomitans, Actinomyces viscosus were detected at high levels in the Turner group $(p<0.05)$.

Conclusion: Besides dental and craniofacial anomalies, clinicians should be alert to the early diagnosis and treatment of periodontal problems in patients with TS.
\end{abstract}

Keywords: Turner syndrome, microarray analysis, oral bacteria

\section{Introduction}

Turner syndrome (TS) is one of the most common chromosomal disorders characterized by typical findings, such as pubertal problems and internal organ anomalies, accompanied by a total or partial loss of an X chromosome (1).

Dental anomalies and orthodontic disorders affecting the maxilla and mandible have been frequently mentioned in TS patients (1-3). Researchers have reported an increased incidence of gingivitis in patients with TS, as well as higher plaque index (PI) and gingival index (GI). Disorders of growth hormone and sex hormones in these patients are thought to increase the susceptibility to gingivitis and periodontitis $(3,4)$. In several other studies, the relationship between changes in sex hormones and gingival diseases has been extensively reported, and the variable effects of oral microbiota due to hormone changes have been reported $(5,6)$.

Besides traditional microbiological studies such as medium, planting, culture and microscopy; molecular genetic studies have also determined the levels of specific species to understand the oral microbiota. Molecular studies in line with new technological possibilities have determined that complex bacterial communities are 
significant in tooth caries and gingival diseases associated with biofilm $(7,8)$.

The aim of this study was to evaluate the oral and dental health of children with TS by determining the bacterial levels related to tooth decay and periodontal diseases.

\section{Materials and Methods}

\section{Study Population}

The study included 20 children with TS aged between 6-18 years and 17 girls aged between 4-18 who were not mentally or physically suffering, followed by the Department of the Pediatric Endocrinology, Department of Child Health and Diseases of the İstanbul Medical Faculty. Mothers and their children, who agreed to participate in the study, were referred to the clinics of the Pediatric Dentistry Department of İstanbul University Faculty of Dentistry. The aim of the study was explained to these children and parents verbally, and the parents signed an informed volunteer form. In the prepared patient information form, the child's age, general health status and medications used were questioned. For this study, ethics committee approval was obtained from the Ethics Committee of İstanbul University Medical Faculty (approval number: 2013/690).

\section{Clinical Examination}

In-mouth examinations of children were performed by the same physician in the reflector light of the dental unit in a sitting position using mirror and sond. The oral and dental health status was assessed according to the recommendations of the World Health Organization by using the decayed-missing-filled teeth (DMFT)-decayedmissing-filled surface (DMFS) / milk teeth: dft, dfs) index (9), $\mathrm{PI}(10)$ and $\mathrm{GI}(10)$ scores. The periodontal index calculation was removed from the study because alveolar bone loss and periodontal pocket formation were not observed in any of the children participating in the study.

\section{Microbiological Sampling}

Patients who underwent an oral examination were directed to the Oral Microbiology Laboratory of İstanbul University Faculty of Dentistry, Department of Basic Medical Sciences for microbiological examination. Saliva samples stimulated by means of sugar-free chewing were taken from all children in the patient and control groups. The patient's saliva-buffering capacities (S-BC) and salivary-flow rates (S-FR) were determined.

\section{Culture}

The saliva samples were 10-fold diluted and then samples of $0.1 \mathrm{~mL}$ were plated on Mitis Salivarius Bacitracin agar (MSB) (Acumedia Man Inc., Baltimore,
Maryland) for mutans streptococci (MS); on Rogosa Agar (Merck, KgaE, Damstadt, Germany) for lactobacilli (LB) and on Sabouraud Dextrose Agar (Merck) for yeast counts. MSB Agar and Rogosa Agar plates were incubated in air supplemented with $5-7 \% \mathrm{CO}_{2}$, while Sabouroud Dextrose Agar plates were incubated aerobically. The samples were incubated for 48 hours at $37^{\circ} \mathrm{C}$. The typical colonies were counted and calculated (cfu/mL). High detection level was; $\geq 10^{5} \mathrm{cfu} / \mathrm{mL}$ for $M S, \geq 10^{4} \mathrm{cfu} / \mathrm{mL}$ for $\mathrm{LB}$ and $\geq 10^{2} \mathrm{cfu} / \mathrm{mL}$ for yeasts; whose detection limits were $10^{3}, 10^{2}$ and $10 \mathrm{cfu} / \mathrm{mL}$ respectively (11).

\section{Microarray}

The remaining $0.5 \mathrm{~mL}$ saliva sample was separated for DNA extraction and stored at $-20{ }^{\circ} \mathrm{C}$. DNA extraction from the stored samples was performed according to the protocol of a ready kit (High Pure polymerase chain reaction (PCR) Template Preparation Kit, Roche, Mannheim, Germany). The obtained DNA samples were stored at $-20^{\circ} \mathrm{C}$. For PCR amplification and hybridization, 10 periodontal bacteria were analyzed in accordance with the instructions of the manufacturer using a specially engineered $16 \mathrm{~S}$ rRNA microarray system (ParoCheck10 ${ }^{\circledR}$, Greiner Bio-One $\mathrm{GmbH}$, Frickenhausen, Germany). The results were directly created using a scanner (CheckScanner ${ }^{\mathrm{T}}$, Greiner Bio-One $\mathrm{GmbH}$ ) and operated by the ParoReport software (ParoCheck ${ }^{\circledR}$ Kit, Gene Pix ${ }^{\circledR}$, Axon Instruments Inc.). It produces a semi-quantitative labelling scheme. The results were classified according to signal levels: no detection, low, moderate, high and very high. The 10 species identified by the ParoCheck $10^{\circledR}$ microarray detection system were as follows: The red complex:Porphyromonas gingivalis, Tannerellaforsythia and Treponema denticola; the orange complex: Campylobacter rectus, Fusobacterium nucleatum, Parvimonas micra and Prevotella intermedia; the green complex: Aggregatibacter actinomycetemcomitans and Eikenella corrodens; the blue complex: Actinomyces viscosus (12).

\section{Statistical Analysis}

The data were analyzed using the IBM SPSS statistics 22 (IBM SPSS, TURKEY) software. Shapiro-Wilk test was used for normality of data analysis. Student's t-test was performed for the analysis of groups according to age, S-FR and buffering capacity, DMFT and dft levels $(p<0.05)$. Mann-Whitney $U$ test was performed to compare results for both groups for the PI and $\mathrm{Gl}$ value $(\mathrm{p}<0.05)$. Mann-Whitney $U$ test was used to assess the presence and levels of bacterial species in samples according to periodontal bacterial associations $(p<0.05)$. The bacterial relationship among the groups based on the detection of the target bacteria in each subject was 
determined by Spearman's (rho) Correlation Coefficient, irrespective of their proportional recovery in samples.

\section{Results}

There was no significant difference in age distribution among the children in the groups. Considering the parameters related to salivary, the groups showed no significant difference for the S-FR $(p=0.45)$ and S-BC $(p=0.37)$ $(p>0.05)$. PI $(p=0.01)$ and $\mathrm{Gl}(p=0.03)$ were significantly higher in the Turner group and dft was significantly higher in the control group $(p<0.05)$ (Table I).

All the children in the Turner group were taking growth hormone. Some patients $(n=9)$ were taking estrogen in addition to growth hormone. However, there was no significant relationship between the drugs used and $\mathrm{PI} / \mathrm{GI}$ levels ( $p>0.05)$.

As a result of the culture examination, there was no significant difference between groups in terms of MS $(p=0.14)$, LB ( $p=1.00)$ and yeast $(p=0.19)$ levels ( $p>0.05)$ (Table II).
Figure 1 shows the prevalence and target levels in different complexes determined by the ParoCheck $1{ }^{\circledR}{ }^{\circledR}$ study:

- Red complex bacteria were seen at low rates in all groups.

- Orange complex bacteria P. intermedia was found to be significantly higher in the Turner group. F. nucleatum was frequently detected in both groups and was significantly higher in the Turner group.

- Green complex bacterium E. corrodens was found to be significantly higher in the Turner group, although it was frequently detected in both groups. A. actinomycetemcomitans was significantly higher in the Turner group.

- Blue complex bacterium A. viscosus was found to be significantly higher in the Turner group.

- Orange complex bacteria C. rectus was not detected in the Turner group. $(p<0.05)$ (Figure 1)

Table III shows the results of the correlation analysis between bacteria:

\begin{tabular}{|l|l|l|l|}
\hline \multicolumn{2}{|l|}{ Table I. Clinical examination findings } & Control ( $\mathbf{n}=\mathbf{1 7})$ & Turner (n=20) \\
\cline { 2 - 4 } & Mean \pm SEM & Mean \pm SEM & p value \\
\hline Age & $12.47 \pm 3.64$ & $13.65 \pm 3.30$ & 0.291 \\
\hline S-FR & $0.66 \pm 0.49$ & $0.77 \pm 0.49$ & 0.459 \\
\hline S-BC & $5.00 \pm 0.57$ & $5.16 \pm 0.50$ & 0.370 \\
\hline PIb & $0.46 \pm 0.60$ & $0.96 \pm 0.70$ & $0.019^{*}$ \\
\hline GIb & $0.17 \pm 0.39$ & $0.47 \pm 0.59$ & $0.033^{*}$ \\
\hline DMFT & $2.41 \pm 1.77$ & $2.10 \pm 2.27$ & 0.411 \\
\hline dft & $2.24 \pm 2.02$ & $0.30 \pm 0.73$ & $0.000^{*}$ \\
\hline
\end{tabular}

Student's t-test, b: Mann-Whitney U test ${ }^{*} \mathrm{p}<0.05$. SEM: Standard error of the mean, S-FR: Salivary flow rates, S-BC: Saliva buffering capacities, PI: Plaque index, GI: Gingival index, DMFT: Decayed-missing-filled teeth

Table II. Distribution of caries-inducing microorganism levels in TS and control group

\begin{tabular}{|c|c|c|c|c|}
\hline & & Control & Turner & \multirow{2}{*}{$p$ value } \\
\hline & & n (\%) & n (\%) & \\
\hline \multirow{3}{*}{ MS } & Low & $1(5.9 \%)$ & $4(20.0 \%)$ & \multirow{3}{*}{0.149} \\
\hline & Medium & $5(29.4 \%)$ & $8(40.0 \%)$ & \\
\hline & High & $11(64.7 \%)$ & $8(40.0 \%)$ & \\
\hline \multirow{3}{*}{ LB } & Low & $5(29.4 \%)$ & $6(30.0 \%)$ & \multirow{3}{*}{1.000} \\
\hline & Medium & 7 (41.2\%) & $8(40.0 \%)$ & \\
\hline & High & $5(29.4 \%)$ & $6(30.0 \%)$ & \\
\hline \multirow{3}{*}{ Yeasts } & Low & $10(58.8 \%)$ & 17 (85.0\%) & \multirow{3}{*}{0.98} \\
\hline & Medium & $6(35.3 \%)$ & 2 (10.0\%) & \\
\hline & High & $1(5.9 \%)$ & $1(5.0 \%)$ & \\
\hline
\end{tabular}

MS: Mutans streptococci, LB: Lactobacilli, Mann-Whitney U test ${ }^{*} p<0.05$ 
- In the Turner group, a positive correlation between $P$. gingivalis and T. denticola $(p=0.768)$ was observed in red complex bacteria.

- In both groups, a positive correlation was found between $T$. denticola from red complex bacteria with $P$. intermedia (control $p=0.483$, Turner $p=0.584$ ), and P. micra (control $p=0.654$, Turner $p=0.684$ ) from orange complex bacteria.

- A positive correlation between F. nucleatum with P. intermedia $(p=0.547)$ and E. corrodens $(p=0.638)$ was observed in the control group.

- There was also a positive correlation between $P$. intermedia and $E$. corrodens $(p=0.643)$ in the control group.

- A. actinomycetemcomitan was positively associated with $A$. viscosus $(p=0.606)$ in the control group and E. corrodens $(p=0.652)$ in the Turner group.

- A negative relationship between bacteria was observed but it was not statistically significant. ( $p<0.05)$ (Table III).

Table IV shows the relationship between the PI and GI values and bacteria:
- In the Turner group, all of the red complex bacteria and $P$. intermedia from orange complex bacteria were significantly correlated with the GI.

- P. gingivalis $(p=0.490), T$. denticola $(p=0.593)$ and $P$. intermedia $(p=0.701)$ were significantly correlated with $\mathrm{PI}$ in the Turner group $(p<0.05)$ (Table IV).

\section{Discussion}

The first detailed study evaluating the mouth symptoms of patients with TS was performed by Flipsson et al. (13) in 1965. There are many unknowns in the craniofacial and dental findings as well as the diagnosis and treatment of this syndrome which has attracted many researchers to date.

Although the DMFT index in patients with TS was significantly lower than in control groups $(3,14,15)$, López et al. (16) found a higher index of caries in the deciduous teeth. Kusiak et al. (14) has reported that these patients may have a higher concentration of S-BC and antibacterial factors such as immunoglobulin A, lactoferrin, lysozyme and a lower DMFT index may be due to salivary properties (3),

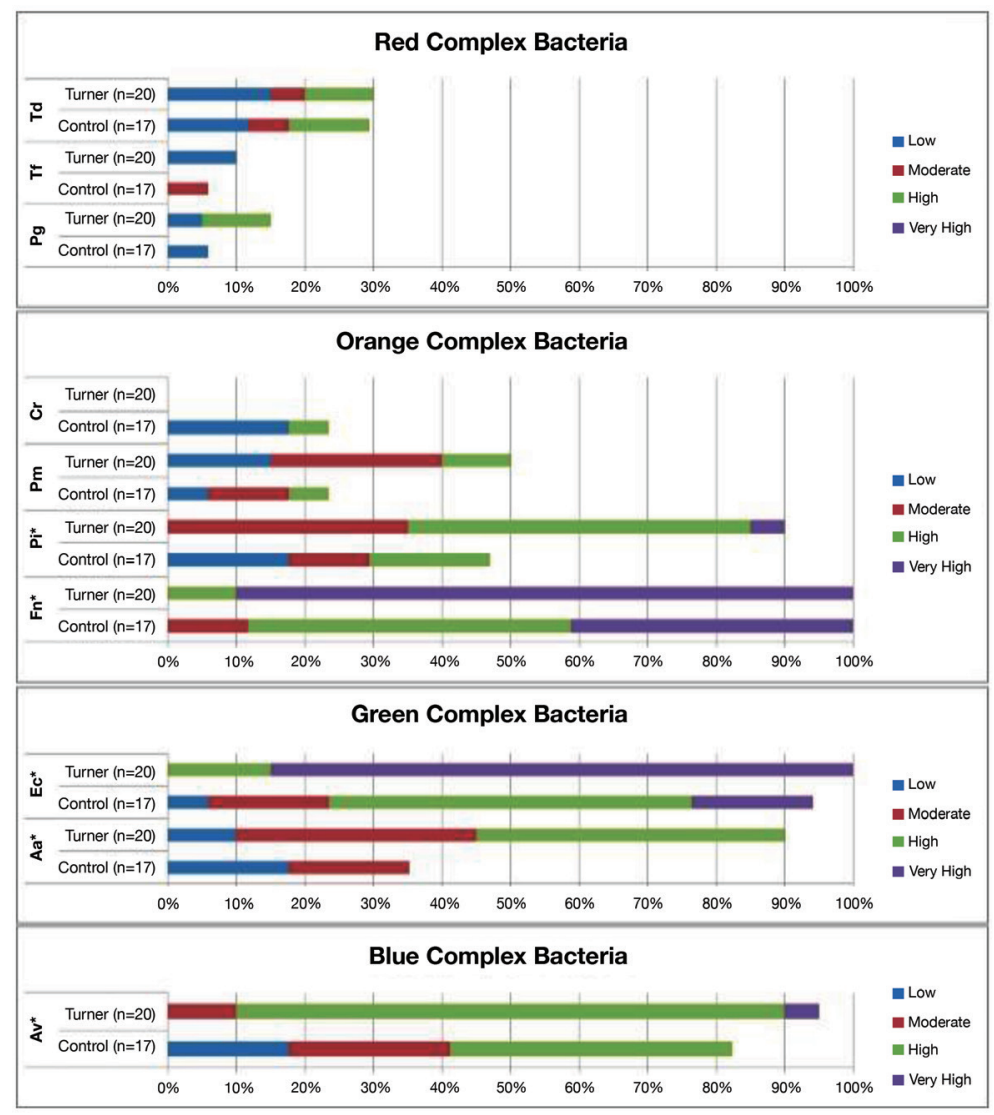

Figure 1. Presence and levels of bacterial species in samples according to periodontal bacterial associations Mann-Whitney U test * $p<0.05$

Td: Treponema denticola, Tf: Tannerella forsythia, Pg: Porphyromonas gingivalis, Cr: Campylobacter rectus, Pm: Parvimonas micra, Pi: Prevotella intermedia, Fn: Fusobacterium nucleatum, Ec: Eikenella corrodens, Aa: Aggregatibacter actinomycetemcomitans Av: Actinomyces viscosus 


\begin{tabular}{|c|c|c|c|c|c|c|c|c|c|c|c|c|c|c|}
\hline & & MS & LB & Yeats & $\mathrm{Pg}$ & Tf & Td & Fn & $\mathbf{P i}$ & $\mathrm{Pm}$ & $\mathrm{Cr}$ & $\mathrm{Aa}$ & Ec & Av \\
\hline \multirow{2}{*}{ MS } & Control & $1.000^{*}$ & 0.093 & 0.384 & -0.304 & -0.304 & -0.277 & -0.241 & 0.000 & -0.453 & 0.150 & $-0.491^{*}$ & -0.162 & -0.425 \\
\hline & Turner & 1.000 & $0.722^{*}$ & $0.468^{*}$ & $-0.460^{*}$ & -0.124 & $-0.475^{*}$ & -0.373 & -0.120 & $-0.541^{*}$ & & 0.193 & 0.104 & $0.520^{*}$ \\
\hline \multirow{2}{*}{ LB } & Control & & 1.000 & 0.288 & 0.000 & -0.326 & -0.331 & 0.430 & 0.102 & 0.000 & -0.211 & 0.000 & $0.563^{*}$ & 0.386 \\
\hline & Turner & & 1.000 & $0.541^{*}$ & -0.351 & -0.215 & -0.194 & 0.000 & 0.178 & -0.260 & & 0.271 & 0.000 & 0.425 \\
\hline \multirow{2}{*}{ Yeats } & Control & & & 1.000 & 0.264 & -0.206 & -0.003 & -0.151 & -0.043 & 0.065 & -0.209 & -0.141 & -0.078 & -0.408 \\
\hline & Turner & & & 1.000 & -0.175 & -0.140 & -0.269 & 0.140 & -0.144 & -0.131 & & 0.232 & 0.176 & 0.104 \\
\hline \multirow{2}{*}{$\mathrm{Pg}$} & Control & & & & 1.000 & -0.063 & 0.381 & 0.281 & 0.389 & 0.343 & -0.138 & 0.421 & 0.056 & 0.268 \\
\hline & Turner & & & & 1.000 & -0.349 & $0.768^{*}$ & 0.140 & 0.318 & $0.610^{*}$ & & 0.242 & 0.176 & -0.177 \\
\hline \multirow{2}{*}{ Tf } & Control & & & & & 1.000 & 0.476 & -0.140 & 0.250 & 0.446 & 0.413 & 0.421 & 0.056 & -0.027 \\
\hline & Turner & & & & & 1.000 & 0.214 & 0.111 & 0.253 & 0.016 & & 0.093 & 0.140 & 0.083 \\
\hline \multirow{2}{*}{$\mathrm{Td}$} & Control & & & & & & 1.000 & 0.034 & $0.483^{*}$ & $0.654^{*}$ & -0.021 & 0.382 & 0.141 & -0.003 \\
\hline & Turner & & & & & & 1.000 & 0.214 & $0.584^{*}$ & $0.684^{*}$ & & 0.220 & 0.270 & -0.092 \\
\hline \multirow{2}{*}{ Fn } & Control & & & & & & & 1.000 & $0.547^{*}$ & 0.113 & -0.091 & 0.238 & $0.638^{*}$ & 0.477 \\
\hline & Turner & & & & & & & 1.000 & 0.016 & 0.312 & & -0.093 & -0.140 & -0.083 \\
\hline \multirow{2}{*}{$\mathrm{Pi}$} & Control & & & & & & & & 1.000 & 0.263 & -0.072 & 0.293 & $0.643^{*}$ & 0.081 \\
\hline & Turner & & & & & & & & 1.000 & 0.215 & & -0.046 & -0.093 & -0.008 \\
\hline \multirow{2}{*}{$\mathrm{Pm}$} & Control & & & & & & & & & 1.000 & 0.000 & 0.206 & 0.122 & 0.011 \\
\hline & Turner & & & & & & & & & 1.000 & & 0.125 & 0.223 & -0.219 \\
\hline \multirow{2}{*}{$\mathrm{Cr}$} & Control & & & & & & & & & & 1.000 & 0.351 & -0.202 & 0.246 \\
\hline & Turner & & & & & & & & & & & & & \\
\hline \multirow{2}{*}{$\mathrm{Aa}$} & Control & & & & & & & & & & & 1.000 & 0.349 & $0.606^{*}$ \\
\hline & Turner & & & & & & & & & & & 1.000 & $0.652^{*}$ & 0.320 \\
\hline \multirow{2}{*}{ Ec } & Control & & & & & & & & & & & & 1.000 & 0.421 \\
\hline & Turner & & & & & & & & & & & & 1.000 & 0.278 \\
\hline \multirow{2}{*}{ Av } & Control & & & & & & & & & & & & & 1.000 \\
\hline & Turner & & & & & & & & & & & & & 1.000 \\
\hline
\end{tabular}

Spearman's (rho) Correlation Coefficient *p<0.05 *Correlation is significant at the 0.05 level. MS: Mutans streptococci, LB: Lactobacilli, Pg: Porphyromonas gingivalis Tf: Tannerella forsythia Td: Treponema denticola, Fn: Fusobacterium nucleatum, Pi: Prevotella intermedia, Pm: Parvimonas micra, Cr: Campylobacter rectus, Aa: Aggregatibacter actinomycetemcomitans, Ec: Eikenella corrodens, Av: Actinomyces viscosus

although the S-FR is slower. In this study, the dft value was significantly higher in the control group $(p<0.05)$, although there was no significant difference between the TS and the DMFT values determined in the control group. When the parameters related to saliva were examined, there was no significant difference between groups in terms of S-FR and $S-B C(p<0.05)$.

In patients with TS, Ogiuchi et al. (4) found that the rate of incidence of gingivitis increased, and Szilágyi et al. (3) found that PI and $\mathrm{GI}$ were significantly high. Väisänen et al. (17) reported that the $\mathrm{Gl}$ and calcular index values of these patients were lower and their periodontal health was better. In this study, PI and GI Turner groups were found to be significantly higher, but no relationship was found between growth hormone and/or estrogen use and $\mathrm{PI}$ and $\mathrm{Gl}$ indexes $(p<0.05)$. It is thought that gingival problems in TS patients are not due to imbalances in growth hormone and estrogen levels but are a consequence of oral ecosystem damage due to a lack of oral hygiene (4), even if changes in sex hormones increase gingivitis and periodontitis susceptibility (6).

In this study, the intra-oral findings of children with TS who were seldom examined in terms of child dentistry were examined and the effect of oral microbiology and hormones on dental and periodontal tissues were evaluated. In this study, no significant difference was found between groups 
in terms of caries-causing microorganisms MS, LB and yeast levels $(p<0.05)$ (Table II).

In this study, the presence and levels of periodontal bacteria in the groups were determined using the semiquantitative microarray system ParoCheck $10^{\circledR}$, which allows for the rapid and reliable detection of 10 different periodontal pathogens (9).

Periodontal diseases are bacterial infections related to the complex microbiosis of tooth biofilm, mainly composed of anaerobic gram-negative species. Although

Table IV. Relation to plaque index and gingival index of bacterial entities

\begin{tabular}{|c|c|c|c|}
\hline & & PI & GI \\
\hline \multirow{2}{*}{ MS } & Control & -0.113 & 0.086 \\
\hline & Turner & -0.380 & $-0.509 *$ \\
\hline \multirow{2}{*}{ LB } & Control & -0.392 & -0.400 \\
\hline & Turner & 0.022 & -0.151 \\
\hline \multirow{2}{*}{ Yeats } & Control & -0.169 & -0.224 \\
\hline & Turner & 0.060 & -0.272 \\
\hline \multirow{2}{*}{$\mathrm{Pg}$} & Control & 0.160 & -0.137 \\
\hline & Turner & $0.490^{*}$ & $0.551^{*}$ \\
\hline \multirow{2}{*}{ Tf } & Control & 0.426 & $0.549^{*}$ \\
\hline & Turner & 0.377 & $0.464^{*}$ \\
\hline \multirow{2}{*}{$\mathrm{Td}$} & Control & 0.299 & 0.061 \\
\hline & Turner & $0.593^{*}$ & $0.657^{*}$ \\
\hline \multirow{2}{*}{$\mathrm{Fn}$} & Control & -0.429 & -0.444 \\
\hline & Turner & 0.363 & 0.359 \\
\hline \multirow{2}{*}{$\mathrm{Pi}$} & Control & -0.075 & -0.022 \\
\hline & Turner & $0.701^{*}$ & $0.659^{*}$ \\
\hline \multirow{2}{*}{$\mathrm{Pm}$} & Control & -0.012 & 0.075 \\
\hline & Turner & 0.341 & 0.338 \\
\hline \multirow{2}{*}{$\mathrm{Cr}$} & Control & 0.587 & 0.721 \\
\hline & Turner & - & - \\
\hline \multirow{2}{*}{$\mathrm{Aa}$} & Control & 0.381 & 0.196 \\
\hline & Turner & -0.107 & -0.160 \\
\hline \multirow{2}{*}{ Ec } & Control & -0.278 & -0.384 \\
\hline & Turner & -0.207 & -0.277 \\
\hline \multirow{2}{*}{ Av } & Control & 0.218 & -0.085 \\
\hline & Turner & -0.384 & -0.230 \\
\hline
\end{tabular}

PI: Plaque index GI: Gingival index, MS: Mutans streptococci, LB: Lactobacilli, Pg: Porphyromonas gingivalis, Tf: Tannerella forsythia, Td: Treponema denticola, Fn: Fusobacterium nucleatum, Pi: Prevotella intermedia, Pm: Parvimonas micra, $\mathrm{Cr}$ : Campylobacter rectus, Aa: Aggregatibacter actinomycetemcomitans, Ec: Eikenella corrodens, Av: Actinomyces viscosus, Spearman's (rho) Correlation Coefficient ${ }^{*} \mathrm{p}<0.05$
A. actinomycetemcomitans and $P$. gingivalis are the most common periodontal pathogens (18), Socransky et al. (19) have identified five consecutive microbial complexes in the subgingival biofilm of individuals with or without periodontal disease, demonstrating that periodontal diseases are due to the co-operation of periodontal microorganisms rather than individual pathogens. In particular, red complex bacteria formed by $P$. gingivalis, $T$. denticola and $T$. forsythia have been reported to show a strong association with periodontal disease and each other.

Griffen et al. (20) found that $P$. gingivalis and T. denticola were related to the disease, and that different species such as Spirochetes and Filifactor alocis should be investigated in relation to periodontitis. da SilvaBoghossian et al. (21) reported that red complex bacteria and $A$. actinomycetemcomitans were highly associated with periodontal disease. Topcuoglu and Kulekci (12) examined different types of periodontitis patients with ParoCheck $10^{\circledR}$ and found that red complex bacteria were common, and that these pathogens were associated with periodontitis.

In this study, red complex bacteria associated with periodontal disease were seen at low rates in all groups. We think that this result is related to the presence of only gingivitis in the children in this study. In this study, P. intermedia and F. nucleatum from orange complex bacteria, $A$. corrodens and $A$. actinomycetemcomitans from green complex bacteria and A. viscosus, which is more related to periodontal health, were significantly higher in the Turner group $(p<0.05)$. Previous studies have shown that some of the disease-related species are also present in samples from healthy individuals and these bacteria, which normally become part of the oral microflora, increase pathogenicity with the degradation of the oral ecosystem $(20,22)$. These results support complex bacterial associations with high gingivitis levels in the Turner group.

In this study, while the red complex bacteria was positively correlated between the each other in the Turner group, a positive correlation was found between the red and orange complex bacteria in both groups. There was also a positive correlation between green complex bacteria in the Turner group. These results support the relationships of bacterial complexes as described by Socransky et al. (19).

In the presented study, all of the red complex bacteria and $P$. intermedia from the orange complex bacteria were significantly associated with the $\mathrm{Gl}(\mathrm{p}<0.05)$. There was a significant correlation between the $\mathrm{PI}$ and periodontal pathogens such as $P$. gingivalis, $T$. denticola, $P$. intermedia in the Turner group $(p<0.05)$. As a result, it should be kept in mind that anaerobic and gram (-) populations increase in 
matured dental plaque biofilm and this ecology poses a risk for gingivitis and periodontitis (23).

\section{Study Limitations}

The research findings of this study were limited by the small number of subjects due to the fact that the children with TS were gathered from just one institution. Therefore, larger studies including more subjects from other institutions may be planned.

\section{Conclusion}

A higher incidence of $P$. intermedia and $F$. nucleatum, A. corrodens, $A$. actinomycetemcomitans and $A$. viscosus as well as higher $\mathrm{PI}$ and $\mathrm{Gl}$ scores suggest an increased susceptibility to periodontal diseases in patients with TS.

\section{Acknowledgment}

This research was supported by the Scientific Research Fund of İstanbul University (approval number: 52942).

\section{Ethics}

Ethics Committee Approval: For this study, ethics committee approval was obtained from the Ethics Committee of İstanbul University Medical Faculty (approval number: 2013/690).

Informed Consent: Informed consent was obtained from the parents or guardians of all eligible children.

Peer-review: Externally peer-reviewed.

\section{Authorship Contributions}

Concept: O.A., G.K., G.Ü., N.T., Design: G.Ü., N.T., Data Collection or Processing: Ş.P., G.Ü., Y.G., Analysis or Interpretation: N.T., G.K., Literature Search: G.Ü., O.A., Y.G., Writing: G.Ü., N.T.

Conflict of Interest: No conflict of interest was declared by the authors.

Financial Disclosure: The authors declared that this study received no financial support

\section{References}

1. http://pediatrics.aappublications.org/content/111/3/692.full. html.

2. Jensen BL. Craniofacial morphology in Turner syndrome. I Craniofac Genet Dev Biol 1985;5:327-40.

3. Szilágyi A, Keszthelyi G, Nagy G, Madléna M. Oral manifestations of patients with Turner syndrome. Oral Surg Oral Med Oral Pathol Oral Radiol Endod 2000;89:577-84.

4. Ogiuchi H, Takano K, Tanaka M, et al. Oro-maxillofacial development in patients with Turner's syndrome. Endocrinol Ipn 1985;32:881-90.
5. Kumar PS. Sex and the subgingival microbiome: do female sex steroids affect periodontal bacteria? Periodontol 2000;61:10324.

6. Mariotti A, Mawhinney M. Endocrinology of sex steroid hormones and cell dynamics in the periodontium. Periodontol 2000;61:69-88.

7. Wade, W.G. The oral microbiome in health and disease. Pharmacological Research 2013;69:137-43.

8. Paster BJ, Dewhirst FE. Molecular microbial diagnosis. Periodontol 2000;51:38-44.

9. World Health Organization. Oral health surveys-basic methods. $4^{\text {th }}$ ed., 1997 Geneva.

10. Silness ), Löe H. Periodontal disease in pregnancy II. Correlation between oral hygiene and periodontal condition. Acta Odontol Scand 1964;22:121-35.

11. Topcuoglu N, Balkanlı O, Yaylalı D, Külekçi G. The effects of the tuft design and toothpaste on the residual microbial contamination of toothbrushes. Turk Hij Den Biyol Derg 2012;69:219-24.

12. Topcuoglu N, Kulekci G. $16 \mathrm{~S}$ rRNA based microarray analysis of ten periodontal bacteria in patients with different forms of periodontitis. Anaerobe 2015;35:35-40.

13. Filipsson R, Lindsten J, Almqvist S. Time of Eruption of the Permanent Teeth, Cephalometric and Tooth Measurement and Sulphation Factor Activity in 45 Patients with Turner's Syndrome with Different Types of X Chromosome Aberrations. Acta Endocrinol (Copenh) 1965;48:91-113.

14. Kusiak A, Kochańska B, Limon J, et al. Buffering capacity and caries prevalence in Turner's syndrome. In Dental Forum 2010;(2):21-5.

15. Takala I, Alvesalo L, Palin-Palokas T, Paunio K, Suoranta K. Caries prevalence in Turner's syndrome $(45, X$ females). I Dent Res 1985;64:126-8.

16. López ME, Bazán C, Lorca IA, Chervonagura A. Oral and clinical characteristics of a group of patients with Turner syndrome. Oral Surg Oral Med Oral Pathol Oral Radiol Endod 2002;94:196204.

17. Väisänen P, Takala I, Alvesalo L. Periodontal health in $45, X$ women (Turner's syndrome). Proc Finn Dent Soc 1989;85:35-40.

18. Slots J, Ting M. Actinobacillus actinomycetemcomitans and Porphyromonas gingivalis in human periodontal disease: occurrence and treatment. Periodontol 2000;20:82-121.

19. Socransky SS, Haffajee AD, Cugini MA, Smith C, Kent RL. Microbial complexes in subgingival plaque. I Clin Periodontol 1998;25:134-44.

20. Griffen AL, Beall C), Campbell JH, et al. Distinct and complex bacterial profiles in human periodontitis and health revealed by 16S pyrosequencing. ISME J 2012;6:1176-85.

21. da Silva-Boghossian CM, do Souto RM, Luiz RR, Colombo AP. Association of red complex, A. actinomycetemcomitans and non-oral bacteria with periodontal diseases. Arch Oral Biol 2011;56:899-906.

22. Scannapieco FA. The oral microbiome: Its role in health and in oral and systemic infections. Clin Microbiol Newsi 2013;35:1639.

23. Seneviratne C), Zhang CF, Samaranayake LP. Dental plaque biofilm in oral health and disease. Chin J Dent Res 2011;14:87-94. 